\title{
EMPRESA E RESPONSABILIDADE SOCIAL: "CIDADE DOS SONHOS" E A PARTICIPAÇÃO NA CONSTRUÇÃO DE POLÍTICAS PÚBLICAS NA CIDADE DE SÃO PAULO
}

\author{
Scarlett da Cunha ${ }^{1}$, Livia de Tommasi ${ }^{2}$
}

\begin{abstract}
Resumo
O intuito do artigo é apresentar uma iniciativa nascida no âmbito da sociedade civil, o "movimento" Cidade dos Sonhos, que atuou no processo de construção do Programa de Metas da cidade de São Paulo (período de 2017 - 2020). Surgida na esfera do setor empresarial e das ações voltadas a legitimar a filantropia empresarial, essa iniciativa se apresenta, no entanto, como um "movimento" social. Se durante o processo de democratização do país o surgimento de uma sociedade civil engajada através de movimentos sociais de caráter popular tem representado o ingresso na política de importantes setores da sociedade até então afastados, num cenário de conflitos, imposições econômicas e de lutas contra as desigualdades, hoje as iniciativas de responsabilidade social empresarial representam um terreno fértil para compreender o atual cenário político, especificamente no que diz respeito à possibilidade de elaborar políticas públicas com a efetiva participação da sociedade civil.
\end{abstract}

Palavras-chave: Políticas Públicas, Movimento, Empresariado, Filantropia empresarial.

\begin{abstract}
The purpose of the article is to present an initiative that was born within the scope of civil society, the "City of Dreams" movement, which acted in the process of building the São Paulo City Goals Program (2017-2020 period). Arising in the sphere of the business sector and actions aimed at legitimizing business philanthropy, this initiative appears, however, as a social "movement". If during the process of democratization of the country the emergence of a civil society engaged through social movements of a popular character has represented the entry into politics of important sectors of society hitherto removed, in a scenario of conflicts, economic impositions and struggles against inequalities, today corporate social responsibility initiatives represent a fertile ground for understanding the current political scenario, specifically regarding the possibility of developing public policies with the effective participation of civil society.
\end{abstract}

Keywords: Public Policy, Movement, Business, Corporate philanthropy.

\footnotetext{
${ }^{1}$ Universidade Federal do ABC. E-mail:scarocunha5@gmail.com

${ }^{2}$ Professora do curso de graduação em Políticas Públicas da Universidade Federal do ABC. E-mail: livia.tommasi@ufabc.edu.br
} 


\section{Introdução}

A sociedade é um conjunto de estruturas em constante transformação. Especialmente no âmbito social, em que se ampliou a necessidade da intervenção do Estado e sua relação com a sociedade civil. Dentro deste cenário surgem organizações, entidades, movimentos sociais, fundações empresariais, sujeitos que vão integrar-se às dinâmicas político-sociais existentes.

Admitindo que as políticas públicas são construídas para responder às demandas expressas por cidadãos que se organizam para fazer ouvir suas necessidades, estes deveriam ser os sujeitos protagonistas, e não simplesmente o "público alvo" de propostas e iniciativas que devem ser sistematizadas em programas e projetos sociais. É de fundamental importância, portanto, entender como a sociedade se organiza para expressar suas demandas, articular propostas e iniciativas, e participar da elaboração de políticas públicas.

É inevitável, quando tratamos de políticas públicas e participação social, pensar nos movimentos sociais, tendo em vista que são grupos organizados que têm como objetivo promover mudanças sociais, econômicas e culturais dentro da sociedade através do embate político e da resistência. No entanto, destoando do que entendemos como movimentos sociais, hoje se encontra na sociedade brasileira uma nova geração de iniciativas, diferentes dos movimentos que surgiram na década de 1970 quando novos atores, novos espaços e novas formas de agir colocaram em questão problemas do cotidiano, existindo, então, um compartilhamento de experiências em comum, de necessidades e sentidos, na construção de propostas e práticas para o enfrentamento dos problemas sociais (SADER, 2001). Enraizados nas associações de bairro, nas lutas populares, na mobilização coletiva, esses movimentos procuravam manter sua autonomia com relação ao Estado e ao mercado (DAGNINO, 2004). Hoje, novas iniciativas que se autodenominam "movimentos" e acreditam que atuam de forma semelhante aos movimentos sociais, promovem a filantropia empresarial e a afirmação de novos paradigmas discursivos e modalidades de ação (PAOLI, 2002). Com elas surge também uma nova gramática, novas concepções que buscam nomear suas formações e composições como "coalizões" e "redes".

Esse é o caso do objeto de estudo deste artigo, a iniciativa "Cidade dos Sonhos", que atuou na construção do Programa de Metas de São Paulo. "Cidade dos Sonhos" é o resultado de uma movimentação realizada através de uma "rede de colaboração" formada por diversas organizações, movimentos e coletivos da sociedade civil e "facilitada" e idealizada pela agência de comunicação "Purpose" (setor empresarial). Essa agência, segundo sua própria definição, tem 
a missão de utilizar a mobilização pública e a narrativa para ajudar organizações, ativistas, empresas, entre outros agentes, em suas lutas.

A "Cidade dos Sonhos" é considerada como um "movimento" por seus integrantes/participantes. Dessa forma, essa iniciativa utiliza a força evocativa desta palavra para legitimar suas ações. Através dessa iniciativa, empresas e organizações/institutos fundadas por empresas assumem um caráter político procurando intervir na tomada de decisões e na formulação de políticas públicas.

O intuito deste estudo foi compreender como foi realizada a participação do "Cidade dos Sonhos" no processo de construção do Programa de Metas da cidade de São Paulo (período de 2017 - 2020), levando em consideração a territorialidade na qual o "movimento" está inserido, suas formas de atuação (mobilização, articulação, atores envolvidos e instrumentos utilizados sobretudo o poder midiático) e sua relação com o poder público. Sendo uma iniciativa impulsionada por uma agência de comunicação (ou seja, uma empresa) que reúne diversos atores politicamente engajados, essa iniciativa representa um caso interessante no atual cenário de mobilização do setor privado.

Para realizar a pesquisa foi feita uma revisão bibliográfica sobre movimentos sociais e participação na construção de políticas públicas e sobre as fundações empresariais, além da revisão de documentos oficiais como a última versão do Programa de Metas da cidade de São Paulo (2017-2020). Foram também recolhidas informações com os responsáveis pela iniciativa na sede da Agência Purpose em São Paulo.

\section{Purpose}

Primeiramente, para compreender o movimento "Cidade dos Sonhos" é importante conhecer os seus bastidores, ou seja, quem foram os responsáveis por idealizar, mobilizar, organizar e reunir diversos atores para realizar um diálogo institucionalizado com o poder público através da elaboração do Programa de Metas da cidade de São Paulo. A Purpose e seus representantes fizeram parte do planejamento estratégico da construção desse movimento.

A Purpose é uma agência de comunicação internacional, cujo objetivo é causar "impactos sociais positivos" através do diálogo com empresas, organizações, ativistas e filantropos, por meio de seus laboratórios de campanhas e desenvolvimento. 
Sua forma de atuação se baseia sobre três abordagens. A primeira consiste na construção de laboratórios que servem de sustentáculos para os movimentos, acreditando que a articulação em massa e a ação coletiva são capazes de promover mudanças na sociedade. O objetivo dos laboratórios é de descobrir e ampliar as melhores abordagens. Além disso, a agência atua como uma consultora, principalmente para empresas, organizações sem fins lucrativos e filantrópicas. Para isso, produz materiais, plataformas digitais que permitem a "democratização da informação", ampliando o alcance de suas ações. Ou seja, o principal viés de atuação é enxergar pautas importantes e movimentos engajados, que possuem potencial de transformação social para investir e otimizar o processo de engajamento, se tornando uma "incubadora" de movimentos sociais.

É uma agência internacional e sua sede no Brasil busca atuar somente na área de mudanças climáticas, em que surgiram as ações denominadas "Cidade dos Sonhos" e "Busão dos sonhos", entre outras iniciativas que atuam simultaneamente em diversas regiões do país.

As principais formas de atuação da Purpose são a participação na tomada de decisões para a construção de políticas públicas e a assessoria para facilitar o acesso aos meios de comunicação por parte da sociedade civil.

Seu orçamento provém dos ganhos obtidos através das contratações, principalmente por parte de empresas, para a realização de atividades voltadas à comunicação e através de financiamentos específicos de empresas e instituições internacionais e nacionais para a realização de projetos em redes, como é o caso do "Cidade dos Sonhos".

\section{Cidade dos Sonhos}

A ideia de estudar a "Cidade dos Sonhos" partiu do contato que tive com a agenda de mobilidade urbana e clima, no âmbito do processo de construção de políticas públicas para a cidade de São Paulo.

A "Cidade dos Sonhos" - movimento sem vínculo partidário - é um conjunto de organizações como a "Ciclocidades", "Minha Sampa", "Instituto Brasileiro de Defesa do Consumidor", "Observatório do Clima", "Rede Nossa São Paulo", entre outros, que trabalham com pautas urbanas e pautas específicas e que atuam dentro dos instrumentos de participação, articulação e comunicação. O principal compromisso desse "movimento" é fazer com que os 
sonhos das pessoas possam transformar suas cidades em ambientes acolhedores, saudáveis e sustentáveis.

\section{Pesquisa do Datafolha - ano de 2016}

O projeto nasceu em 2016, através da Purpose, com o objetivo de contribuir para que os candidatos às eleições municipais de 2016 e a mídia debatessem soluções para os problemas da cidade em quatro temas fundamentais: áreas verdes, energia limpa, mobilidade urbana e resíduos sólidos no Rio de Janeiro, São Paulo e Recife. O propósito inicial era inserir na agenda dos candidatos à eleição de 2016 esses quatro temas. Mesmo se a questão ambiental não era central nas discussões políticas, apostava-se que essa seria uma agenda decisiva no momento da escolha eleitoral.

Para recolher as opiniões da sociedade civil de maneira a impactar as agendas políticas, o "movimento" Cidade dos Sonhos - enquanto ação conjunta - encomendou uma pesquisa ao Datafolha, divulgada em cerimônia realizada no dia 18 de agosto de 2016, para medir a reação da população sobre os temas propostos.

Segundo a pesquisa ${ }^{3}$, da qual participaram 1400 pessoas registrando seus "sonhos" sobre as temáticas propostas, $45 \%$ dos participantes disseram que "certamente mudariam o voto" caso o candidato não apresentasse propostas adequadas para as quatro temáticas. As três principais demandas que apareceram exercendo uma maior influência sobre a população foram o "fim dos lixões", a "coleta seletiva para todos" e "mais áreas verdes", mostrando que a população valorizava as políticas voltadas para o meio ambiente ${ }^{4}$.

Após a consolidação das reflexões trazidas pela pesquisa e considerando que os temas propostos tiveram uma maior visibilidade perante a população, assumindo a relevância da agenda ambiental para a sociedade civil em diversos âmbito - principalmente midiático - os atores envolvidos na "Cidade dos Sonhos" trouxeram para o cerne da discussão uma questão que iria norteá-los nas próximas ações: "Como os sonhos podem virar realidade?"

\footnotetext{
${ }^{3}$ Não obtive acesso a pesquisa e nem a sua metodologia, porque não estão disponíveis, apenas tive conhecimento por parte da Ana Neca e também com informações coletadas através deste site: http:/www.cbnribeirao.com.br/politica/NOT,2,2,1194114,Meio+ambiente+e+sustentabilidade+podem+mudar+o+vo to+do+eleitor.aspx e também existem mais informações da Rede Nossa São Paulo: http://nossasaopaulo.org.br/portal/arquivos/pesquisamobilidade2017.pdf

${ }^{4}$ Informações sobre as demandas da população por meio ambiente também não estão disponíveis e de fácil acesso, mas foi encontrada algumas informações sobre neste site http://portal.aprendiz.uol.com.br/2016/08/22/cidade-dossonhos-aposta-em-participacao-social-para-criar-cidades-sustentaveis/
} 


\section{Programa de Metas}

Presente atualmente em 49 cidades brasileiras sendo 20 delas no Estado de São Paulo, segundo levantamento da Rede Nossa São Paulo, o Programa de Metas foi uma iniciativa da Rede Nossa São Paulo. A lei do Programa de Metas de São Paulo, instituído através da emenda n³0 à Lei Orgânica do Município de SP (projeto de emenda à LOM Nº8/07) que determina que toda prefeita/o eleita/o ou reeleita/o apresente o Programa de Metas de sua gestão em até noventa dias após a posse. O programa deve conter as ações estratégicas, indicadores e metas quantitativas para cada setor da Administração Pública Municipal, Subprefeituras e distritos da cidade, trazendo as principais diretrizes de sua campanha eleitoral e as demais normas da Lei do Plano Diretor Estratégico do Município de São Paulo (Lei N 16.050, de 31 de julho de 2014).

A lei prevê também a realização de audiências públicas nos 30 dias seguintes à apresentação do Plano de Metas. A/o prefeita/o também deverá prestar contas à população a cada seis meses e publicar um relatório anual sobre o cumprimento das metas.

Em teoria este arcabouço institucional é uma maneira da população da cidade conhecer as prioridades da atual gestão municipal e assim cobrar o que de fato está sendo implementado durante os quatro anos do mandato. O Plano deveria ter influência direta na definição orçamentária do município. A Lei do Programa de Metas define que periodicamente deve ser divulgado quanto das metas foi atingido, permitindo à sociedade acompanhar e avaliar objetivamente a gestão municipal. Assim, nas intenções, torna-se uma ferramenta importante para permitir o controle social, planejamento urbano e incentivo à cultura do monitoramento das políticas públicas.

Admitindo que o Programa de Metas é uma ferramenta de controle social e admitindo também a necessidade por parte da população de se apropriar desta ferramenta para conhecer as prioridades da gestão municipal e cobrar o cumprimento das metas estipuladas ao longo dos quatro anos de gestão, a "Cidade dos Sonhos" enxergou uma oportunidade de atuação, entendendo que sua intervenção seria crucial para promover uma maior visibilidade à discussão das metas.

Com base nos preceitos da "Cidade dos Sonhos" e o diálogo realizado junto à Rede Nossa São Paulo, uma das parceiras da "Cidade dos Sonhos", foi considerado que para os sonhos virarem metas (para além de promessas) era preciso ter lastro legal, inclusive na questão dos 
orçamentos destinados a cada área temática, ou seja, seria preciso que esses sonhos coletados ${ }^{5}$ se tornassem metas legais.

A Rede Nossa São Paulo, por ser a pioneira, já realizava suas ações compreendendo o contexto do Programa de Metas, principalmente na construção da política. Desta forma, com o contato direto com a RNSP, o "movimento" Cidade dos Sonhos passou a incorporá-lo também por compreender a importância dele enquanto instrumento legal.

Após a ação realizada no período eleitoral, em 2016, a Cidade dos Sonhos definiu como próximos passos a inserção desses "sonhos" nas ações de governo. Sendo assim, os integrantes passaram a estudar o Programa de Metas para utilizá-lo como instrumento de participação popular, de modo a torná-lo mais acessível às demandas da sociedade civil e incluir as demandas já identificadas. O foco de atuação foi o Programa de Metas da Cidade de São Paulo (2017-2020) na gestão do Prefeito João Dória.

\section{Programa de Metas - Cidade de São Paulo 2017-2020}

Embora já tenha existido Programa de Metas nas duas gestões anteriores com Kassab (2009-2012) e Haddad (2013-2016), este instrumento ainda é pouco conhecido pela sociedade civil. O movimento "Cidade dos Sonhos" buscou atuar na democratização do acesso à informação deste instrumento, ao mesmo tempo em que buscou garantir que a prefeitura se comprometesse com as decisões tomadas.

O objetivo foi utilizar o Programa como ferramenta para introduzir as discussões sobre mobilidade urbana e sustentabilidade, de modo que as demandas pudessem ser respaldadas em lei. Segundo o relatório oficial publicado recentemente pelo movimento "Cidades do Sonhos", toda a campanha foi baseada no conceito de que o Programa de Metas é um antídoto contra as promessas vazias feitas nas campanhas eleitorais.

Supostamente, hoje cada prefeito e prefeita de cidades com a Lei do Programa de Metas já aprovada tem prazos, formatos e agenda estipulados para a participação da sociedade. Apesar da versão final do Programa de Metas ser decisão da/o prefeita/o, ou seja, não é obrigatório que as propostas da população sejam acolhidas, é essencial que haja uma participação ativa da sociedade nesse processo, tanto na agenda de consulta pública prevista nas Leis (realização de

\footnotetext{
${ }^{5}$ Os sonhos coletados podem ser visualizados em https://cidadedossonhos.org/category/sonhos/areas-verdes 
audiências públicas, por exemplo), quanto em ações ampliadas como a estruturação e o encaminhamento prévio de propostas dos moradores e instituições da sociedade civil à gestão municipal.

Segundo os integrantes da Purpose, foram encontrados uma série de obstáculos para a realização do projeto, dos quais o principal foi a não universalidade do Programa de Metas, ou seja, cada cidade possui uma legislação específica quanto a existência do Programa. Recife, por exemplo, não possui uma lei específica para a criação de um Programa de Metas, fazendo com que a mobilização da Cidade dos Sonhos, neste local, ficasse paralisada.

Em janeiro de 2017, João Dória toma posse como Prefeito da Cidade de São Paulo e junto com ele é nomeado Paulo Uebel como Secretário de Gestão - secretaria responsável pela coordenação do Programa de Metas em São Paulo. A nova gestão apresentou uma proposta de ampliação da participação da sociedade civil na formulação do programa. O instrumento utilizado para tal ação foi a disponibilização de uma plataforma online para receber a colaboração da sociedade - sendo essa a primeira vez que o munícipe pode contribuir com o Programa de Metas pela internet e antes da apresentação oficial da primeira versão à sociedade. Para acessar a plataforma disponibilizada pela prefeitura era necessário um cadastro prévio e responder à questão: "Qual seu sonho para o futuro da cidade de São Paulo?"6. Em seguida, escolher três categorias em que o sonho se encaixe e por último, responder à pergunta "Qual projeto devemos fazer para que seu sonho para São Paulo vire realidade?". Ou seja, objetivo da atual gestão foi de ampliar a participação da sociedade civil na construção desta ferramenta através de consulta pública digital. A formulação das perguntas transparece a influência de termos "apelativos", neste caso "sonhos", cujo objetivo é transmitir a sensação de que sonhos podem ser realizados porque podem ser transformados em metas.

\section{Primeira Versão do Programa de Metas (2017-2020) - Gestão Dória}

No dia 30 de março de 2017, a Prefeitura de São Paulo divulgou a primeira versão do Programa de Metas, mas o "Cidade dos Sonhos" considerou que no documento não havia

\footnotetext{
${ }^{6}$ Para saber mais informações, acessar: http://www.prefeitura.sp.gov.br/cidade/secretarias/gestao/noticias/?p=231917 
referência explicita a como as metas seriam alcançadas: não estavam colocados indicadores nem uma previsão orçamentária para as iniciativas serem realizadas.

A "Cidade dos Sonhos" promove então oficinas de avaliação da primeira versão do Programa de Metas dividindo-as por temas: no dia 01 de abril de 2017 foi discutido sobre áreas verdes e resíduos, e no dia 03 de abril de 2017 sobre mobilidade urbana.

Após a apresentação da Primeira Versão do Programa de Metas foi aberto o período das audiências públicas, realizadas ao longo de um mês e finalizadas em 30 de abril de 2017. Além disso, a prefeitura disponibilizou uma plataforma online para manifestação de sugestões e críticas e um e-mail para o envio de contribuições.

A não divulgação dos calendários das audiências por parte do poder público dificultou o acesso a esses canais de participação, implicando na não concretização da participação real da população. Sendo assim, a "Cidade dos Sonhos", passou a atuar mais no sentido de democratizar o acesso a informação através da divulgação de vídeos informativos e presença forte nas redes sociais.

Na gestão do Kassab a participação da sociedade civil na formulação do Programa de Metas foi baixa se comparada com a gestão do Haddad, quando houve um aumento dos canais de participação através de audiências públicas e conselhos, entre outros. Esperava-se que essa participação, já regulamentada em lei, pudesse ser mantida na gestão Dória, mas isso não ocorreu. As audiências públicas foram agendadas "em cima da hora", o calendário demorou para ser disponibilizado e quando foi publicado restavam poucos dias para mobilizar a população para participar efetivamente das audiências. Além disso, muitas audiências ocorreram simultaneamente em várias regiões da cidade, ou seja, em diversos locais no mesmo dia e horário; ocorreram em horários comerciais, de modo que o trabalhador não conseguiria participar. O que pode ser percebido é que mesmo abrindo formalmente canais de participação, o poder público se utiliza de diversas estratégias para continuar inviabilizando a participação e atuação dos cidadãos.

A plataforma disponibilizada pela Prefeitura exigia uma série de informações pessoais do cidadão, sem contar na dificuldade do acesso o que também inviabilizava a participação. Outro ponto negativo foi a ausência de divulgação nas grandes mídias.

\section{Mídia como principal instrumento de mobilização e alcance}


Tendo como principal organizador a Purpose, uma agência de comunicação, esperava-se que o movimento "Cidade dos Sonhos" concentraria seus esforços nos setores da comunicação, principalmente de campanhas midiáticas. Deste modo, após a divulgação do calendário sobre a construção do Programa de Metas em São Paulo, este "movimento" articulou mais atores engajados na agenda de mobilidade urbana para produzir um material que mostrasse para a sociedade civil e demais organizações o que era o programa de metas, de maneira a promover a "democratização da informação".

Com isso, foi elaborado um material audiovisual ${ }^{7}$ - em vídeo - que foi disponibilizado no próprio site da "Cidade dos sonhos" e também nas redes sociais, consideradas um importante instrumento de divulgação de informação (mesmo ainda muito restrito por que muitas pessoas não possuem acesso à Facebook ou tem interesse em ter, de maneira que a informação fica limitada a quem tem).

Paralelamente à campanha virtual, foram organizados encontros com a sociedade civil, chamados de "Ciclos de encontros", ações de rua através da \#MetasdeSp, onde as pessoas podiam tirar selfies ao lado de um boneco de dois metros de altura do prefeito João Doria com placas indicando as metas que apoiavam para a cidade, como: Implantação de 260 quilômetros de faixas e corredores de ônibus, oferta de coleta seletiva em $100 \%$ das residências, instalação de painéis de energia solar em $70 \%$ das 1.500 escolas municipais, criação de 47 novos parques e $100 \%$ do transporte público com combustíveis limpos.

Após a compilação das propostas mais votadas, estas, em forma de documentos temáticos, foram encaminhadas ao prefeito João Doria, às secretarias responsáveis por cada tema e ao secretário de gestão Paulo Uebel, solicitando a inclusão das propostas no Programa de Metas. Além disso, o "movimento" apresentou um documento técnico sobre cada agenda, composto pelas sugestões da sociedade civil. As organizações participantes do "movimento" foram facilitadoras do processo contribuindo com a parte técnica e de tradução dos termos, de modo a tornar a linguagem acessível. A divulgação ficou por conta da Purpose.

No dia 06 de julho, a "Cidade dos Sonhos" e sua equipe técnica elaboraram uma avaliação do Programa de metas com respeito às iniciativas apresentadas. Feito isso, protocolaram essa avaliação na prefeitura realizando, na ocasião, uma coletiva de imprensa

\footnotetext{
${ }^{7} \mathrm{O}$ material audiovisual pode ser visto através do site https://cidadedossonhos.org/\#programa-de-metas
} 
motivada pela percepção dos integrantes do "movimento" que para pressionar a gestão municipal não funcionariam somente ações nas ruas, protestos ou conteúdo divulgado em redes sociais, pois a gestão Dória é marcada pela sua força midiática. Portanto, decidiram utilizar a mídia como ferramenta de pressão para forçar a gestão a responder sobre as pendências nos canais de participação e a responder sobre as demandas surgidas no processo de construção do Programa de Metas.

Sendo assim, transformaram esse documento em uma petição para que o mesmo pudesse ser mais acessível. Divulgaram no site (www.metasdesp.minhasampa.org.br) os temas para serem votados. Ou seja, nesse momento de avaliação do Programa de Metas foram realizadas diversas articulações: assessoria técnica para a elaboração do documento, somada a um trabalho de imprensa forte e a campanhas realizadas nas ruas (escolheram 12 lugares diferentes da cidade de São Paulo para a realização das ações) e em redes sociais.

Amplificando a estratégia de participação midiática, o "movimento" esteve presente no SPTV - Jornal da Globo, o que representa um grande alcance de divulgação das demandas da população que não seria possível obter sem o apoio e influência da Purpose como agência de comunicação.

\section{Repercussão}

Todas as articulações promovidas pela Cidade dos Sonhos, mas diretamente facilitadas e só possibilitadas graças à atuação da Purpose, promoveram a participação de 3.197 pessoas.

Ao final do processo, haviam propostas que coincidiam - algumas parcialmente - com as metas apresentadas pela gestão no Programa de Metas. Em outras, através da pressão e cobrança apresentada através dos diversos canais midiáticos (redes sociais, plataformas online, campanhas, vídeos e até participações em canais de Tv aberta), houve um aumento nos compromissos assumidos. Mas também tiveram propostas que não entraram na versão Final do Programa de Metas.

Segundo o relatório oficial publicado recentemente pela "Cidade dos Sonhos" desde o início do processo de construção do Programa de Metas a proposta da "coalizão de entidades da sociedade civil" foi de apresentar à gestão municipal demandas solidamente embasadas em argumentos técnicos. Essa postura teve por objetivo principal minimizar o risco de que as sugestões fossem ignoradas. 
Ao final, de todas as propostas elaboradas e sugeridas na construção do Programa de Metas de São Paulo, a mais expressiva foi no âmbito da agenda de Mudanças Climáticas, especificamente na Meta 28: "Reduzir em 15\% (156.649 ton) a emissão de CO2, em 50\% (37 ton) a emissão de material particulado e em 40\% (1.999 ton) a emissão de NOx pela frota de ônibus municipais até 2020". Na primeira versão do Programa de Metas não havia menção ao combate às emissões de Gases de Efeito Estufa (GEE), mas essa foi introduzida na versão final, ainda que com limitações.

\section{Análise Crítica}

Um quadro de imposições econômicas, desigualdades e conflitos, ajuda a entender a necessidade e a importância do surgimento de uma sociedade civil engajada através de movimentos sociais autônomos e politizados, no sentido de que a demanda direta da população é importante.

Nos últimos decênios o empresariado se engajou de forma significativa no âmbito da sociedade civil brasileira, buscando legitimar este engajamento enquanto "responsabilidade social", de maneira a desenvolver uma "consciência cidadã" dentro da classe empresarial, através da promoção da filantropia empresarial (PAOLI, 2002). A perspectiva da responsabilidade empresarial encontrou na sociedade um espaço próprio, conhecido como "terceiro setor", que junto com organizações não governamentais assume a postura de contribuir, no âmbito privado, com a redefinição das políticas públicas. Este grupo assume a ineficiência do Estado como um dado, ressaltando que o Estado não possui recursos suficientes e/ou que não sabem "gastá-lo" com políticas efetivas para melhorar a situação social. Frente a essa ineficiência estatal, o setor privado forneceria um exemplo de eficiência e eficácia o que justificaria seu engajamento no enfrentamento dos problemas sociais. Este apelo ao comprometimento social do setor privado é inédito na história brasileira.

O objeto de estudo deste artigo, o "movimento" Cidade dos Sonhos, exemplifica bem a atuação desse novo ator, representando uma nova forma de mobilização que é difícil encaixar no conceito de "movimento social", sendo fruto da idealização (da Purpose) e articulação realizada entre uma empresa (Purpose) e outras entidades para atuar no âmbito das políticas públicas. A origem da "demanda" por um movimento que atuasse no âmbito das mudanças climáticas partiu 
da agência de comunicação aqui mencionada, que articulou organizações engajadas na temática para angariar mudanças na sociedade através da política do Programa de Metas.

A linguagem utilizada pela filantropia empresarial justifica e legitima sua existência e atuação. Assim, as expressões "filantropia", "responsabilidade social", "investimento social" se tornaram corriqueiras. Essa característica não se restringe só as ações, mas também à forma como se identificam, como "coalizão", "rede de parceiros", "colaboradores" como é o caso da "Cidade dos Sonhos", que se auto-denomina "movimento" outrora "coalizão".

Segundo Maria Celia Paoli (2002), "essa "filantropia empresarial cidadã" e sua autoinvestida na responsabilidade social no Brasil está indiretamente ligada à substituição da ideia de deliberação participativa". Deste modo, por um lado a "Cidade dos Sonhos" promove ações nas ruas, campanhas nas redes sociais para coletar os "sonhos" da sociedade civil; por outro lado a participação dos cidadãos fica restrita a esse âmbito dos "sonhos". Por mais inovadoras que sejam suas ações, ainda predomina o conservadorismo dentro da solidariedade privada, que implica em "retirar da arena política e pública os conflitos distributivos e a demanda coletiva por cidadania e igualdade" (PAOLI, 2002).

Segundo Evelina Dagnino (2004), o que ocorre nessas práticas de participação é a predominância de uma zona nebulosa que dificulta o discernimento sobre os sentidos da participação. Como a autora coloca, houve uma "confluência perversa" entre um discurso participativo democrático e um discurso neoliberal, os dois reivindicando uma participação ativa da população no enfrentamento dos problemas sociais. No entanto, o projeto neoliberal enfraquece as instituições estatais democráticas, substituindo a ação estatal com a atuação do setor privado, individualizando os problemas sociais e responsabilizando os cidadãos para sua solução. Esse deslocamento é perceptível no "movimento Cidade dos Sonhos", tendo em vista a sua conformação - uma coalizão de organizações que se diz porta voz das demandas da sociedade.

O mais significativo das ações da "Cidade dos Sonhos" é a capacidade de utilizar a mídia a seu favor para pressionar o poder público. A Purpose, enquanto Agência de Comunicação, uniu seu conhecimento e seu potencial de comunicação para utilizar a mídia. Ao mesmo tempo, procurou canais de "participação" institucionais para influir sobre a construção de políticas públicas. Mas, de fato, a população continuou não ocupando esses espaços (no caso, as audiências públicas). Somente "participou" expressando seus "sonhos" numa plataforma online. 
Ou seja, a população contribuiu com os "sonhos", mas não estavam presentes nos espaços de discussão e de tomadas de decisão. Nesse tipo de ação o que pareceu importar foi divulgar a Agência Purpose e a marca "Cidade dos Sonhos" para "vender" seu nome e iniciativa.

Outro ponto acerca deste "movimento" é que enquanto supostamente procura democratizar as informações e as discussões com o poder público, de modo a torná-las mais acessíveis, as informações acerca das próprias ações da "Cidade dos Sonhos" não são muito acessíveis, já que não foi possível localizar a pesquisa no site do Datafolha. Ou seja, existe uma contradição entre exigir transparência do poder público e não tornar transparentes os próprios dados e informações coletadas.

Também é importante ressaltar a escolha do nome "movimento" Cidade dos Sonhos. Essa noção de que os sonhos podem tornar-se metas tem um apelo significativo. Veicula a ideia de que os sonhos são possíveis de serem realizados e que é possível pensar "grande". É uma estratégia de marketing. Muitas dessas empresas nem sequer possuem setores específicos para promoção do trabalho social, restando apenas a atuação do departamento de marketing. "Informe aqui os seus sonhos para a cidade", faz transparecer a ideia de que está ao alcance da sociedade a decisão sobre o futuro de sua cidade.

Percebe-se que o "movimento" Cidade dos Sonhos tem uma natureza muito distinta dos movimentos descritos no trabalho do sociólogo Eder Sader que analisa a atuação dos chamados "novos movimentos sociais" ativos durante o processo de redemocratização, nos anos 70 e 80 (SADER, 2001). Naquele momento, quem se mobilizava eram trabalhadores, donas de casa, grupos de bairro ligados à Igreja Católica, sindicatos, que buscavam reivindicar a democracia através de lutas no cotidiano para alcançar a melhoria das condições de vida da maioria da população. Ao contrário, o "movimento Cidade dos Sonhos" parece estar mais atrelado à ascensão do poder político das empresas, de sua influência sobre as tomadas de decisão e a formulação de políticas. A noção de "movimento" veicula a ideia de um "todo", de um ator coletivo, mas no fundo a intenção é garantir um "selo" de responsabilidade social e a divulgação da sua "marca". A ação social passa a ser uma oportunidade de negócio, agregando valor à marca que financia o "movimento".

Esse tipo de "movimento" explora as compatibilidades entre lucro e "filantropia", cria uma linguagem própria de cidadania, cria sua forma própria de participação na agenda pública, favorecendo, porém, os interesses privados - Purpose enquanto empresa e sede no Brasil, idealiza 
a demanda de construir um movimento (composto por organizações já engajadas) que atue na agenda das mudanças climáticas de maneira a promover "impacto e responsabilidade social." Vale ressaltar que é possível reconhecer o potencial de inovação e mobilização que o setor empresarial possui. Entretanto, não se pode dizer que os projetos em vigor, como o "Cidade dos Sonhos" promovam impactos sociais significativos. A noção de impacto, como pode ser visto nas repercussões deste "movimento", é mais relativa aos números de indivíduos que participaram das pesquisas, ao alcance no espaço midiático do que a transformações sociais concretas na sociedade.

Por fim, entende-se que por mais sensível que as empresas sejam às desigualdades sociais existentes, elas preservam hierarquias. Deste modo, segundo Maria Celia Paoli (2002), falta o essencial a este "movimento" das elites, aquilo que os direitos sociais, por lei, garantem: um espaço público real. Em todo caso, a atuação desses novos "movimentos" representa um terreno fértil para futuras investigações no campo das políticas públicas, no âmbito das quais o setor empresarial se tornou um agente político importante. 


\section{Referências Bibliográficas}

DAGNINO, Evelina. “¿Sociedade civil, participação e cidadania: de que estamos falando?”. In MATO, Daniel. Políticas de Ciudadanía y Sociedad Civil en tiempos de globalización Caracas, edição de FACES, Universidad Central de Venezuela, 2004.

De sonhos à realidade: Metas para São Paulo. Cidades dos Sonhos. Relatório. São Paulo, 2018.

OLIVEIRA, Francisco. Do liberalismo à social-democracia: a desprivatização da democracia. In TEIXEIRA, Ana Claudia. Os sentidos da democracia e da participação. São Paulo: Instituto Pólis, 2005.

PAOLI, Maria Célia - "Empresas e responsabilidade social: Os enredamentos da cidadania no Brasil" (Capítulo 08) In SANTOS, Boaventura de S. (Org). "Democratizar a Democracia: Os Caminhos Da Democracia Participativa" - Rio de Janeiro: Civilização Brasileira, 2002.

Plano de Metas 2017-2020. Prefeitura de São Paulo. São Paulo, 2016.

SADER, Eder. Quando novos personagens entraram em cena: experiências, falas e lutas dos trabalhadores da Grande São Paulo, 1970-80. Rio de Janeiro: Paz e Terra, 4a edição 2001.

Sobre a Campanha \#MetasdeSP. Disponível em: $<$ https://cidadedossonhos.org/tag/programa-demetas>. Acesso em: 10 de Junho de 2018.

SÃO PAULO. Lei n. 16.050, de 31 de julho de 2014. Aprova a política de desenvolvimento urbano e o plano diretor estratégico do município de São Paulo e revoga a lei n.13.430/2002.

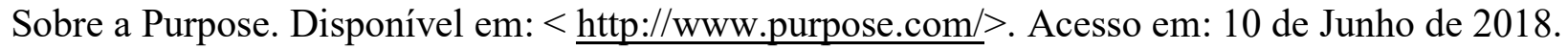

Sobre o Cidade dos Sonhos. Disponível em: < https:/g1.globo.com/sao-paulo/noticia/entidadessocioambientais-criticam-metas-do-plano-de-doria-vagas-e-timidas.ghtml $>$. Acesso em 10 de Junho de 2018. 